\title{
OPTIMASI WAKTU TUNGGU LAMPU LALU LINTAS DENGAN MENGGUNAKAN GRAF KOMPATIBEL SEBAGAI UPAYA MENGURANGI KEMACETAN
}

\author{
Aris Fanani ${ }^{1)}$ \\ ${ }^{1)}$ Program Studi Matematika, Fakultas Sains dan Matematika \\ UIN Sunan Ampel Surabaya \\ e-mail: arisfa@uinsby.ac.id ${ }^{1)}$
}

\begin{abstract}
Kemacetan lalu lintas di beberapa kota sudah menjadi hal yang tak asing lagi, bahkan sampai persimpangan jalan. Kemacetan timbul dikarenakan beberapa hal, salah satunya adalah konflik pergerakan yang datang dari tiap arah. Tujuan dari pembuatan jurnal ini adalah untuk menentukan waktu tunggu yang optimal pada lampu lalu intas dengan menggunakan graf kompatibel. Dalam penelitian ini menggunakan data primer pada persimpangan frontage BRI-Dinas Perhubungan dan LLAJ - Jl. Ahmad Yani Surabaya dengan menggunakan variabel waktu. Berdasarkan penelitian yang dilakukan memberikan hasil bahwa (1) graf kompatibel pada persiampangan frontage BRI-Dinas Perhubungan dan LLAJ - Jl. Ahmad Yani Surabaya, (2) hasil yang didapat di lapangan adalah 150 deik, sedangkan dengan menggunakan graf kompatibel menghasilkan 120 detik. Dengan menggunakan graf kompatibel, penentuan waktu tunggu lebih optimal dari pengaturan yang sudah ada.
\end{abstract}

Kata Kunci: Graf Kompatibel, Waktu Tunggu, Lampu Lalu Lintas

\section{Abstract}

Traffic congestion in cities has become a familiar, even to a crossroads. Congestion is caused by several things, one of which is the conflict of the movement coming from every direction. The purpose in this paper is to determine the optimal waiting time at traffic lights by using a compatible graph. In this study using primary data on the crossing frontage BRI-Department of Transportation and LLAJ Jl. Ahmad Yani Surabaya by using a variable time. Based on the research results that graf compatible on frontage BRI-Department of Transportation and LLAJ - Jl. Ahmad Yani Surabaya. The results obtained in the field is 150 seconds, while using a compatible graph produces 120 seconds. By using compatible graph, determination waiting time is more optimal than existing arrangements.

Keywords: traffic flow,RMSE, artificial neural networks, support vector machines, svm-pso rentet prediction time

\section{PENDAHULUAN}

Dalam perkembangan zaman dan teknologi, dewasa ini membutuhkan peranan matematika sebagai dasar perkembangan ilmu pengetahuan dan teknologi. Dengan demikian, hampir dapat dipastikan bahwa setiap bagian dari ilmu pengetahuan dan teknologi, baik ilmu murni maupun ilmu terapan akan memerlukan peran matematika sebagai ilmu bantunya.

Salahsatu bagian dari matematika dalam aplikasi kehidupan sehari-hari adalah graf. Dalam kehidupan sehari-hari graf digunakan untuk menggambarkan berbagai struktur yang ada. Tujuannya adalah sebagai visualisasi objek-objek agar lebih mudah dimengerti. Teori graf merupakan salah satu cabang dari matematika yang bermanfaat di berbagai bidang ilmu. Salah satu contohnya, graf kompatibilitas sering digunakan untuk menentukan waktu tunggu total dan mengatur pergerakan arus lalu lintas.

Kemacetan lalu lintas di suatu kota atau tempat sekarang ini bukan merupakan hal yang asing lagi yang dapat terjadi di suatu ruas ataupun persimpangan jalan. Kemacetan timbul karena adanya konflik pergerakan yang datang tiap arah kaki simpangnya dan untuk mengurangi konflik ini banyak dilakukan pengendalian untuk mengoptimalkan persimpangan dengan menggunakan lampu lalu lintas.

\section{DASAR TEORI}

Teori graf merupakan cabang dari matematika yang telah ada lebih dari dua puluh dekade yang lalu. Jurnal pertama tentang teori graf pada tahun 1736 oleh Euler dari Swiss. 


\subsection{Definisi Graf}

Sebuah graf $\mathrm{G}$ berisikan dua himpunan yaitu himpunan berhingga tak kosong $\mathrm{V}(\mathrm{G})$ dari objekobjek yang disebut titik dan himpunan berhingga (mungkin kosong) $\mathrm{E}(\mathrm{G})$ yang elemen-elemennya disebut sisi sedemikian hingga setiap elemen e dalam $\mathrm{E}(\mathrm{G})$ merupakan pasangan tak berurutan dari titik-titik di V(G) disebut himpunan titik G.

Graf didefinisikan sebagai pasangan himpunan $(\mathrm{V}, \mathrm{E})$, ditulis dengan notasi $\mathrm{G}=(\mathrm{V}, \mathrm{E})$, yang dalam hal ini adalah himpunan tidak kosong dari titiktitik (vertices atau node) dan adalah himpunan sisi (edges atau arcs) yang menghubungkan sepasang titik, E boleh kosong. Jadi, sebuah graf dimungkinkan tidak mempunyai sisi, tetapi titiknya harus ada minimal satu. Graf yang hanya mempunyai satu buah titik tanpa sisi dinamakan graf trivial.

\subsection{Graf Kompatibel}

Graf-graf kompatibilitas digunakan secara luas dalam memecahkan masalah yang melibatkan pengaturan data dalam urutan tertentu. Dalam graf kompatibilitas, vertex menunjukkan objek-objek yang akan diatur, dan edge menunjukkan pasangan objek yang kompatibel (sesuai).

\subsection{Teori Transportasi}

Persimpangan jalan adalah suatu daerah umum di mana dua atau lebih ruas jalan (link) saling bertemu atau berpotongan yang mencakup fasilitas jalur jalan (roadway) dan tepi jalan (road side), di mana lalu lintas dapat bergerak di dalamnya.

Pergerakan lalu lintas ini dikendalikan berbagai cara, bergantung pada jenis persimpangannya. Dilihat dari bentuknya ada beberapa macam jenis persimpangan sebidang, sebagai berkut:

a) Pertemuan atau persimpangan sebidang bercabangtiga.

b) Pertemuan atau persimpangan sebidang bercabangempat.

c) Pertemuan atau persimpangan sebidang bercabangbanyak.

d) Bundaran (RotaryIntersection)

\section{METODOLOGI PENELITIAN}

Untuk melakukan penelitian harus memperhatkan prosedur dan langkah- langkah yang akan dilakukan untuk memulai penelitian. Langkah-langkah dasar yaitu persiapan penelitian, pelaksanaan penelitian dan pelaporan. Adapun alur yang digunakan dalam jurnal ini seperti pada (Gambar1)

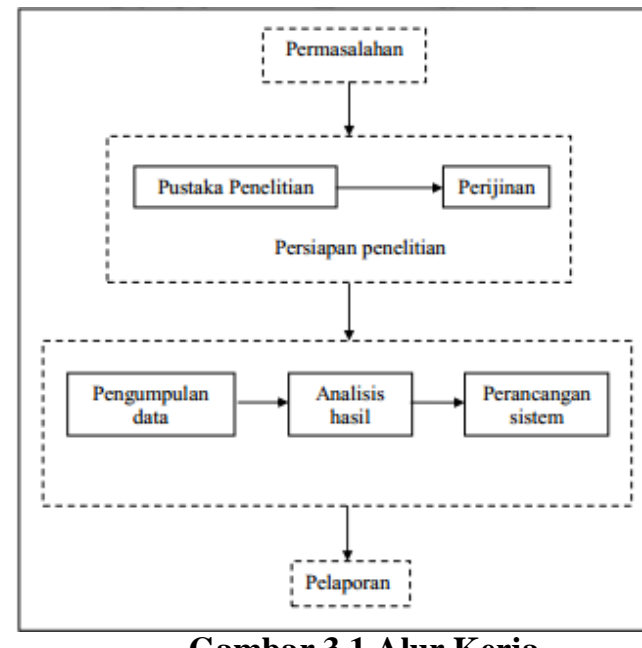

Gambar 3.1 Alur Kerja

\subsection{Tempat dan Waktu Penelitian}

Lokasi Penelitian di persiampangan frontage BRI-Dinas Perhubungan dan LLAJ - Jl. Ahmad Yani Surabaya. Bagian yang diamati adalah beberapa waktu tunggu total optimal padalampu lalu lintas. Waktu penelitian dilakukan pada pagi, siang, dan sore.

\subsection{Teknik Pengumpulan Data}

Metode yang digunakan dalam penelitian ini adalah metode observasi yang merupakan metode pengumpulan data dengan cara pengamatan atau peninjauan langsung terhadap objek penelitian. Objek dari penelitian ini adalah jumlah kendaraan serta jumlah jalur yang ada pada persimpangan frontage BRI - Dinas Perhubungan dan LLAJ - Jl. Ahmad Yani Surabaya. Hasil dari pengambilan data akan disajikan dalam bentuk graf kompatibel. Data yang diambil dianggap telah mewakili dalam hari-hari biasa.

\section{HASIL DAN PEMBAHASAN}

Dalam pembahasan jurnal ini mengkaji tentang penerapan graf kompatibel untuk pengaturan lalu lintas di persimpangan jalan, dengan lokasi penelitian pada persimpangan frontage BRI Dinas Perhubungan dan LLAJ Jl. Ahmad Yani Surabaya. Penelitian ini memerlukan data tentang bentuk persimpangan jalan serta menentukan arus yang terjadi pada persimpangantersebut.

\subsection{Penerapan Graf Kompatibel pada Penentuan Waktu Tunggu Total Optimal di Persimpangan Jalan}

Berdasarkan pengamatan yang dilakukan di lapangan, dibuat gambar persimpangan tersebut 


\section{SYSTEMIC}

Vol. 02, No. 01, Agustus 2016, 45- 50

kemudian diubah kedalam bentuk graf kompatibel. Sebelum mengubah ke dalam bentuk graf kompatibel, diperoleh definisi arus lalu lintas yang kompatibel, yaitu: dua buah arus lalu lintas dikatakan kompatibel jika keduanya dapat berjalan bersamaan dengan aman atau tidak berpotongan.

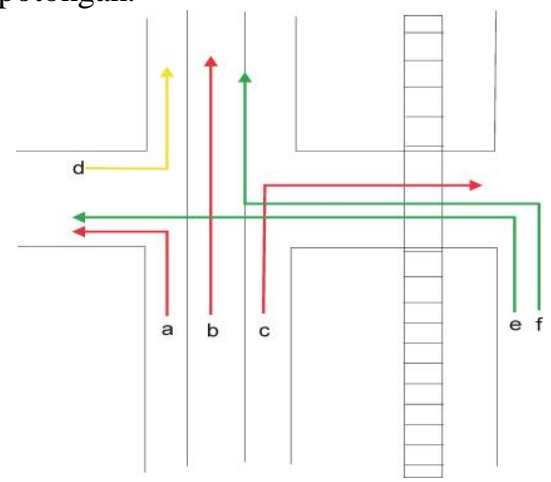

Gambar 4.1 Ruas Jalan Hasil Pengamatan

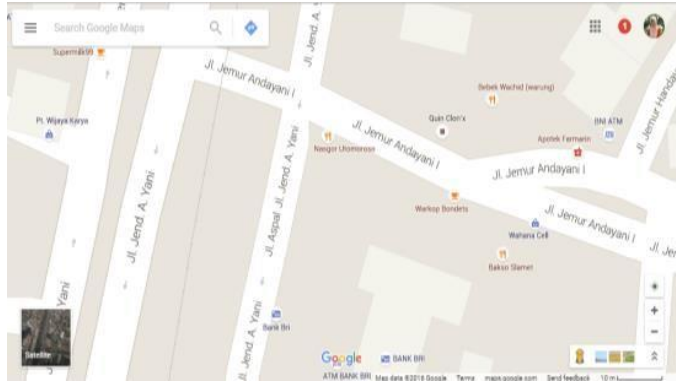

Gambar 4.2 Peta persimpanganfrontage BRI - Dinas Perhubungan dan LLAJ - Jl. Ahmad Yani Surabaya

Tabel 4.1 Data Waktu Optimasi

1. Pengambilan data I (Jum'at, $10 \mathrm{Juni}$ 2016) pada pagi hari pukul $07.00 \mathrm{WIB}-08.00$ WIB

\begin{tabular}{|l|c|c|c|}
\hline \multirow{2}{*}{ Pengamatan Awal } & Merah & Kuning & Hijau \\
\cline { 2 - 4 } & (detik) & (detik) & (detik) \\
\hline Jalan Frontage (A) & 30 & 3 & 45 \\
\hline Jalan Ahmad Yani (B) & 40 & 3 & 30 \\
\hline Jalan Dishub (C) & 65 & 3 & 30 \\
\hline
\end{tabular}

2. Pengambilan data II (Jum'at, 10 Juni 2016) pada siang hari pukul 13.00 WIB-14.00 WIB

\begin{tabular}{|l|c|c|c|}
\hline \multirow{2}{*}{ Pengamatan Awal } & Merah & Kuning & Hijau \\
\cline { 2 - 4 } & (detik) & (detik) & (detik) \\
\hline Jalan Frontage (A) & 30 & 3 & 45 \\
\hline Jalan Ahmad Yani (B) & 40 & 3 & 30 \\
\hline Jalan Dishub (C) & 65 & 3 & 30 \\
\hline
\end{tabular}

3. Pengambilan data III (Jum'at, 10 Juni 2016) pada sore hari pukul 17.00 WIB-18.00 WIB

\begin{tabular}{|l|c|c|c|}
\hline \multirow{2}{*}{ Pengamatan Awal } & Merah & Kuning & Hijau \\
\cline { 2 - 4 } & (detik) & (detik) & (detik) \\
\hline Jalan Frontage (A) & 30 & 3 & 45 \\
\hline Jalan Ahmad Yani (B) & 40 & 3 & 30 \\
\hline Jalan Dishub (C) & 65 & 3 & 30 \\
\hline
\end{tabular}

lall unlyall tya wantu yally volucua. Ially dilakukan pada pagi, siang, dan sore hari. Berdasarkan hasil yang didapat setelah dilakukan pengamatan d lapangan, data yang diperoleh menunjukkan sama dalam pengambilan pada waktu yang berbeda seperti pada (Tabel 1 ). Dari hasil pengamatan yang sudah dilakukan pada waktu yang berbeda, diperoleh siklus lampu lalu lintas pada Persimpangan tersebut sama. Hal ini sangat tidak efisien, dikarenakan berdasarkan jumlah atau kepadatan kendaraan yang melintas pada waktu pagi, siang, dan sore berbeda.

\subsection{Pembahasan}

Pemodelan graf kompatibel pada masingmasing persimpangan diawali dengan penggambaran bentuk persimpangan serta arus yang terjadi pada persimpangan kemudian dilakukan mencari subgraf lengkap terbesar. Untuk lokasi persimpangan frontage BRI - Dinas Perhubungan dan LLAJ - Jl. Ahmad Yani Surabaya.

Dalam objek persiampangan frontage BRIDinas Perhubungan dan LLAJ - Jl. Ahmad Yani Surabaya, tedapat 6 objek yaitu a, b, c, d, e, dan $\mathrm{f}$ sesuai ilustrasi berikutini. Dari ilustrasi di atas, dapat diketahui bahwa terdapat beberapa arus lalu lintas yang kompatibel salah satunya adalah arus a kompatibel dengan b dan c. Dari siklus lampu lalu lintas di atas dapat diketahui graf kompatibel yang terbentuk sebagai berikut.

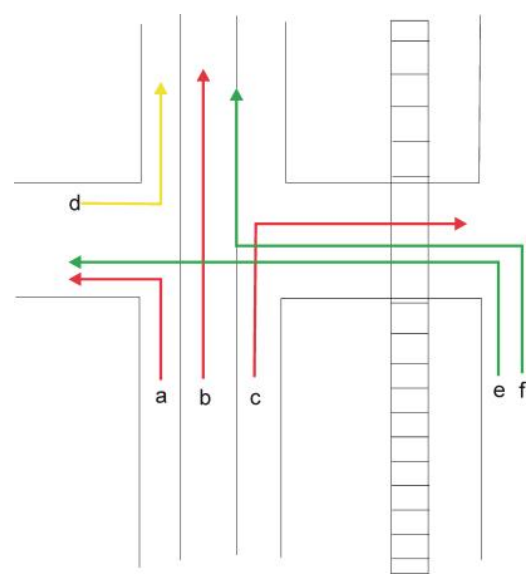

Gambar 4.3 Graf Kompatibel

Selanjutnya, akan dicari subgraf terbesar yang terbentuk yaitu (semua ada)Sehingga memiliki himpunan titik $\{a b c, d, e f\}$. Terdapat tiga subgraf yang terbentuk, yaitu:

Asumsikan satu putaran lalu lintas 60 detik. 60: $3=20$ detik. Terdapat 3,2, 1 titik yang terbentuk sehingga $3 \times 20=60,2 \times 20=40,1 \times 20=$ 20. Untuk lebih jelasnya dapat dilihat pada diagram jam berikut

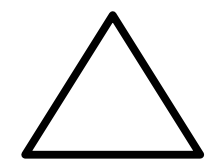

Gambar 4.4 Subgarf Jika Semua Arus Mengikuti Lampu Lalu Lintas 


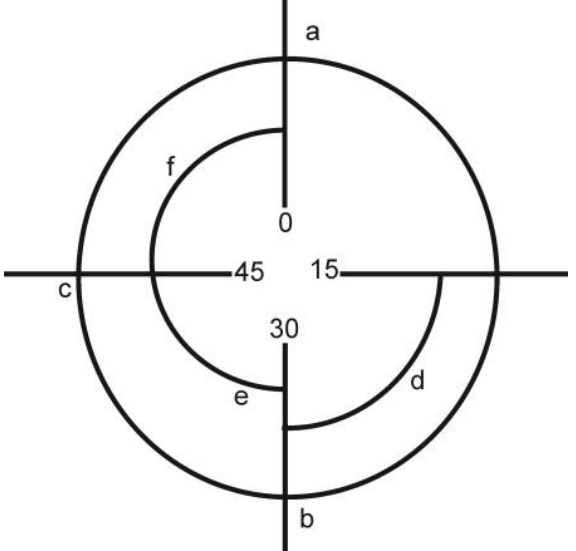

Gambar 4.5. Diagram Jam Semua arus Mengikuti Lampu Lalu Lintas

Dan waktu tunggu totalnya adalah $6 \times 20=$ 120 detik. Namun, pada saat arus d tidak mengikuti lampu lalu lintas sesuai dengan graf kompatibel yan terbentuk:

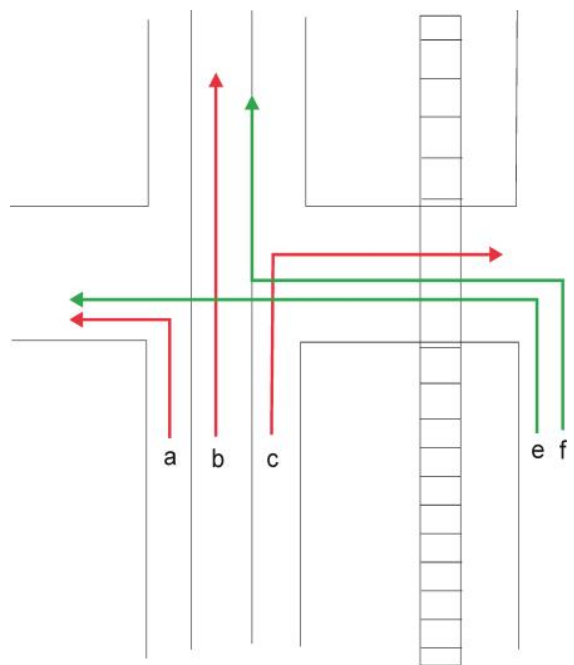

Gambar 4.6. Graf Kompatibel Jika Arus d Tidak Mengikuti Lampu Lalu Lintas

akan didapatkan himpunan titik \{abc, ef $\}$. Sehingga terdapat dua subgraf lengkap yaitu pada gambar 4.7.

Asumsikan 1 putaran $=60$ detik. $60: 2=30$. Sehingga terdapat 3 dan 2 titik. 3 x $30=90$ dan 2 $\mathrm{x} 0=60$.

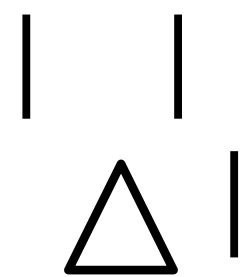

Gambar 4.7. Subgraf Jika Arus d Tidak Mengikuti Lampu Lalu Lintas

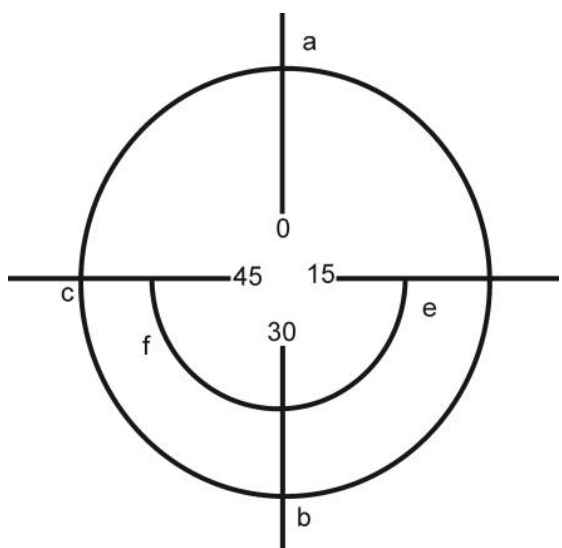

Gambar 4.8. Diagram Jam Arus d

Tidak Mengikuti Lampu Lalu Lintas

Waktu tunggu totalnya adalah 5 x $30=150$ detik. Saat ini jika arus a tidak mengikuti lalu lintas, seperrti gambar di bawah ini:

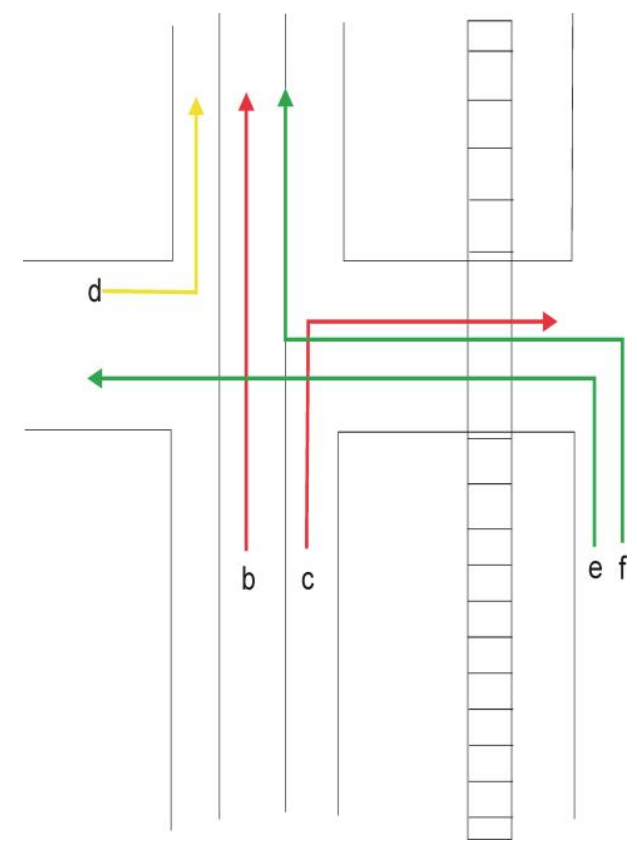

Gambar 4.9 Graf Kompatibel Jika Arus a Tidak Mengikuti Lampu Lalu Lintas

Maka akan memiliki himpunan titik $\{b c, d, e f\}$. Maka terdapat 3 subgraf lengkap sebagaiberikut:

Gambar 4.10. Subgraf Jika Arus a Tidak Mengikuti Lampu Lalu Intas

Asumsikan 1 putaran lampu lalu lintas $=60$ detik. $60: 3=20$. Maka, terdapat 2dan 1 titik. $2 \times 20=$ 40 dan $1 \times 20=20$ detik. 
SYSTEMIC

Vol. 02, No. 01, Agustus 2016, 45- 50

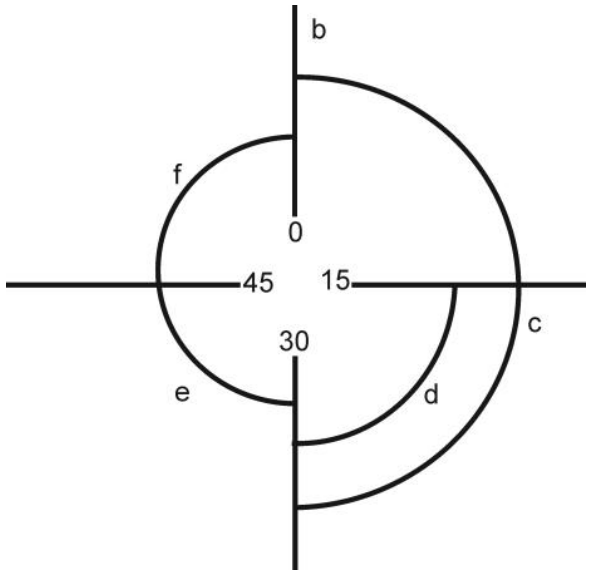

Gambar 4.11. Diagram Jam Arus a

Tidak Mengikuti Lampu Lalu Lintas

Sehinggawaktu tunggu totalnya adalah 5 x $20=100$ detik. Untuk selanjutnya jika a dan d tidak mengikuti lampu seperti gambar di bawah ini:

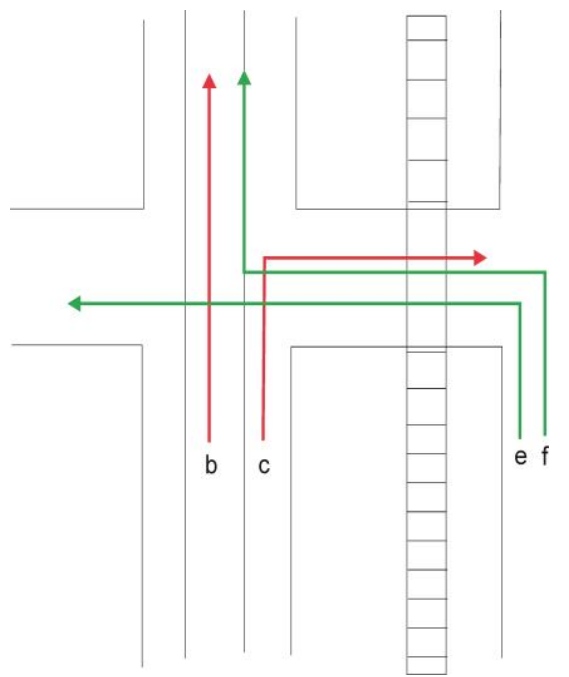

Gambar 4.12 Graf Kompatibel Jika Arus a dan d Tidak Mengikuti Lampu Lalu Lintas

Maka, terdapat dua himpunan titik $\{b c$, ef) dan terdapat duasubgraf.

$$
\mid
$$

Gambar 4.13. Subgraf Jika Arus a dan d Tidak Mengikuti Lampu Lalu Lintas

Asumsikan bahwa 1 putaran adalah 60detik. $60: 2=30$ detik. Terdapatdua titik $2 \times 30=60$ detik. Tidak Mengikuti Lampu Lalu Lintas Sehingga waktu tunggu totalnya adalah 4 × $30=120$ detik.

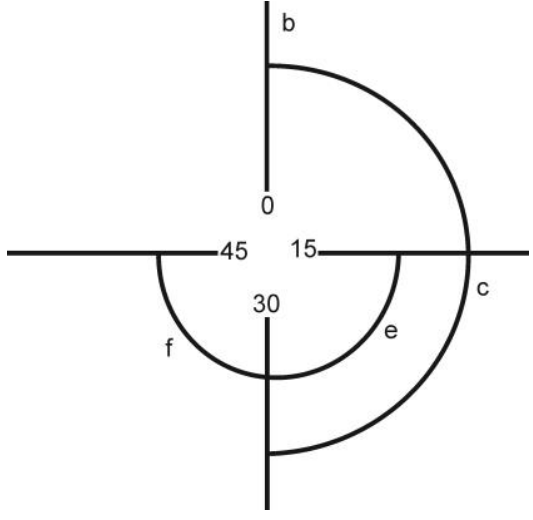

Gambar 4.14. Diagram Jam Arus a dan d

\section{KESIMPULAN}

Dengan menggunakan graf kompatibel, kita dapat memperoleh waktu tunggu yang optimal pada lalu lintas. Sehingga, dapat mengurangi kemacetan yang terjadi khususnya di persimpangan frontage BRI - Dinas Perhubungan dan LLAJ - Jl. Ahmad Yani Surabaya dengan optimasi waktu 100 detik untuk tiap wakttu tunggu total. Dari beberapa permisalan di atas, dapat disimpulkan bahwa jika arus a tidak mengikuti lampu lalu lintas maka akan mendapatkan waktu tunggu yang optimal dari yang lain yaitu 100 detik yang tentunya berbeda dengan kenyataan yang menggunakan arus $d$ yang tidak mengikuti lampu lalu lintas.

\section{DAFTAR PUSTAKA}

[1]Baruah, A.K, \&Baruah, Niky. 2012. Signal Group of Compatible Graph in Traffic Control Problems. Int. J. Advanced Networking and Applications. Vol:04 Issue:01 Pages: 1473-1480 ISSN: 09750290

[2]Budayasa,I.K.2007.Teorigraf dan Aplikaisnya. Surabaya :Unesa UniversityPress.

[3]Hariyanto,J.2004.SistemPengendalianLalu LintasPadaPertem uanJalanSebidang. Sumatera Utara: Jurnal Jurusan Teknik Sipil Universitas SumateraUtara.

[4] Kusuma, Sri dan Hari Purnomo.2013. Aplikasi Logika Fuzzy.Yogyakarta:GrahaIlmu

[5]Kusumadewi,Sri.2002.Analisis dan Desain Sistem Fuzzy Menggunakan Tool Box Matlab. Yogyakarta:GrahaIlmu.

[6]Munir,R.2005.MatematikaDiskrit. Bandung: Informatika

[7]Nugroho,A.D.2008.Analisis Penerapan Belok Kiri Langsung Terh adap Tundaan Lalu Lintas Pada Pendekat 
Persimpangan Bersinyal.

Tesis.Semarang: Program Magister Teknik Sipil Universitas Diponegoro 